\title{
Editorial: Joint Action: What Is Shared?
}

\author{
Stephen A. Butterfill • Natalie Sebanz
}

Published online: 24 June 2011

(C) Springer Science+Business Media B.V. 2011

What did you do today? It is likely that some of your answers to this question refer to things you did individually and others to things you did jointly with others. In commonsense thinking about action and intention, the notion that some actions have two or more agents seems unproblematic. An activity like Ayesha and Beatrice's carrying a two-handled picnic basket together does not, on the face of it, seem harder to understand in everyday life than Ayesha's carrying the basket alone. From this point of view, to restrict attention to actions with just one agent seems arbitrary. But in developmental, cognitive and philosophical research there is a long tradition of focusing exclusively on actions with just one agent, and a range of questions arise when one attempts to generalise from individual to joint action.

In inquiries concerning agency and action, philosophers have developed theories which link intention, reasons, motivation and (occasionally) emotion. These theories generally apply to individual action only and not all of them can be straightforwardly generalised to joint action. For instance, consider how intentional action is related to intending. It is quite widely agreed that an action can be both intentional and a shooting without being an intentional shooting, and also that one way for an action to be an intentional shooting is for it to be appropriately related to an intention to shoot. How does this idea apply to joint actions? Consider Ayesha and Beatrice, who carry a two-handled basket together. If their joint carrying is to be an intentional joint carrying, then it is not enough that Ayesha and Beatrice each individually intend to carry the basket. After all, their having these intentions is consistent with each planning to act alone. But there is much disagreement concerning what is sufficient for joint actions to be intentional as joint actions. Some hold that this involves a special attitude (Kutz 2000; Searle 1990[2002]) while others have explored the idea

\footnotetext{
S. A. Butterfill $(\bowtie)$

Department of Philosophy, University of Warwick, Coventry, UK

e-mail: s.butterfill@warwick.ac.uk

N. Sebanz

Centre for Cognition, Donders Institute for Brain, Cognition, \& Behaviour, Radboud University, Nijmegen, The Netherlands
} 
that it may involve a special kind of subject, a plural agent (Helm, 2008), a special kind of reasoning, team reasoning (Gold and Sugden 2007), or distinctive patterns of interlocking obligations or commitments (Gilbert 1992; Roth 2004). Opposing all such views, Michael Bratman $(1992,2009)$ argues that shared intentions can be realised by multiple ordinary individual intentions and other attitudes whose contents interlock in a distinctive way. The diversity of views indicates the difficulty involved in understanding what is required for joint actions to be intentional as joint actions. Here and elsewhere in the philosophy of action it is not straightforward to generalise claims about action from individual to joint action.

Philosophical inquiries concerning the roles of intention, motivation, reason and emotion in joint action are intricately interwoven with questions about psychological mechanisms for joint action. In developmental psychology, joint action is closely connected with research on theory of mind and its precursors. With respect to a particular notion of joint action, we can ask which theory of mind abilities are required to engage in joint action, and also whether there are theory of mind abilities whose acquisition might be facilitated by abilities to engage in joint action. One obstacle to pursuing such questions is uncertainty over which notion or notions of joint action matter for understanding development. According to Tomasello and Rakoczy, forms of cooperative activity which appear around infants' first birthdays are "all manifestations of a single underlying social-cognitive skill". They call this skill shared intentionality and characterise it as "the understanding of persons as intentional agents who have a perspective on the world that can be followed into, directed, and shared" (Tomasello and Rakoczy 2003: 125). On this view, joint action of the sort children in their second year engage in already presupposes a relatively sophisticated understanding of others' minds. An alternative view would hold that cooperative activities may manifest multiple social abilities some of which do not fall under Tomasello and Rakoczy's notion of shared intentionality. A key cluster of questions for understanding development, then, concern which abilities are required for particular forms of joint action.

In cognitive psychology, research on action focuses on mechanisms linking an agent's reasoning, thoughts and emotions to her bodily movements. It is widely assumed that actions such as reaching for and grasping a tennis ball involve a hierarchical structure of plans (Hamilton and Grafton 2007). A high level plan might be an abstract specification of the action outcome to be achieved (to grasp the ball), whereas an intermediate level would detail the type of grasp to be used (whole-hand) while lower levels specify the aperture of the grasp needed, particulars of the movement trajectory and the force required to secure the ball. A major question is then how approaches to individual action planning and motor control can be extended to account for joint task performance, and how acting together modulates individual cognitive processes. There is considerable evidence to suggest that people form representations of their co-actor's tasks that are, at least in some respects, functionally equivalent to representations guiding their own actions (Knoblich et al. 2011). However, more work is needed to specify how exactly others' tasks are represented, in what ways representations of self and other are equivalent, and how "shared" representations (in the sense of equivalent) facilitate coordination. Research on interpersonal coordination is also concerned with the question of how internal 
models that generate predictions about one's own actions can be applied to predict the outcomes and the timing of others' actions (Wolpert et al. 2003).

Overall, then, joint action raises a tangle of philosophical, developmental and cognitive questions. Many of these questions are naturally understood to be about sharing, about the sharing of intentions, emotions, task representations, and action plans. Of course it is not easy to explain what it means to share in this context. Few researchers hold that agents can literally share intentions, emotions or other states in the sense in which two siblings share a parent; and while it is uncontroversial that agents can share intentions, emotions and other states in the sense in which siblings share genes, on almost any account this kind of sharing is not sufficient for joint action. The overarching question in this special issue is which forms of sharing (if any) are needed to explain the development of joint action, to characterise the mechanisms which make effective joint action possible and to explain what joint action is. In the following we will explain how the papers in this special issue contribute to answering this question and, in some cases, raise new puzzles.

\section{Themes and Controversies in this Special Issue}

In her contribution Pacherie provides a new analysis of the intentions required for intentional joint action. Actions are events which are intentional under some description. Accounts of shared intention can be seen as attempts to explain how this idea, given prominence by Donald Davidson (see Davidson 1971 [1980]), applies in cases of joint action. As Pacherie argues, existing accounts of shared intention tend to require sophisticated abilities to identify the knowledge, intentions and commitments of other agents. Drawing on work by Bacharach, Pacherie offers an alternative approach to shared intention. She proposes that for two or more agents to share an intention to $\mathrm{A}$ is for each to conceive herself as a member of a team consisting of all the agents, each to reason that $\mathrm{A}$ is the best action for the team as a whole, and each to therefore intend to do her part of A. If this is right, shared intention places only modest demands on agents' mindreading abilities: it requires them to detect other agents and to attribute goals, but not to ascribe propositional attitudes such as knowledge or intention. One interesting feature of Pacherie's proposal is the absence of any common knowledge requirement. Her view entails that two agents could share an intention without knowing that they do, and perhaps even despite believing that they do not.

Where Pacherie is concerned with the sort of structure that constitutes a shared intention, others have focused on questions about the objects of intention. A central problem for accounts of joint action concerns what can be intended about actions which involve doing things jointly with others. Smith presents a new puzzle concerning intentions to act jointly with others. As he argues, it seems that one can freely perform an intentional joint action and, simultaneously, without irrationality, believe that this joint action is not the best available option. In Smith's example, Stan and Ollie have bought a piano and can either have it delivered or carry it home themselves. Ollie is convinced that they ought not to carry the piano. Despite this, at Stan's insistence, they freely decide that, jointly, they will carry the piano home; and they act on this decision. It seems to follow from this that Ollie intends that, jointly, 
he and Stan carry the piano. However, Ollie also believes that he and Stan ought not to carry the piano. So it seems that Ollie freely intends something which he believes ought not to be done. This would make Ollie criticizably irrational. But Ollie is not being criticizably irrational; he is making the best of things by giving in to his stubborn friend. If this is right, it cannot be true that Ollie intends that he and Stan jointly carry the piano. So we face a dilemma. If Ollie doesn't intend that he and Stan jointly carry the piano, how can Ollie's carrying the piano with Stan be an intentional activity? But if Ollie does intend this, how does he avoid irrationality despite believing that their action is not the best available option? In resolving this dilemma Smith clarifies the notion of intending to play one's part in a joint action. On the view he offers, for Ollie and Stan to intend to play their parts it is sufficient that Ollie and Stan each have an intention where these intentions are such that, necessarily, both intentions are satisfied just if, jointly, Ollie and Stan carry the piano home.

There is an interesting point of contact between Pacherie's and Smith's contributions. Pacherie's central idea is that shared intention involves team reasoning, that is, reasoning about what it would be best for us collectively to do. Smith, in defending his otherwise very different proposal, distinguishes between Ollie considering what he should do and Ollie considering what he and Stan should do. Despite many differences, it does seem that some contrast between individual and joint perspectives on what is to be done plays an important role in both Pacherie's and Smith's accounts. As we shall explain, the contrast is further analysed in Woodard's contribution and it is important in Elliot's contribution as well.

Blomberg, like Smith, is concerned with what agents involved in a joint action can intend. As Blomberg notes, it is widely accepted and plausibly true that "what one attempts are one's own actions" (Bratman 1992, p. 330). Consider Blomberg's example of two ice skaters performing a manoeuvre requiring coordinated bodily movements. The fact that an agent can attempt to perform only actions which are her own actions appears to entail that neither skater can attempt to perform this manoeuvre. This appears true because the manoeuvre involves both agents acting. Blomberg argues, however, that the apparent entailment does not hold because one skater can experience the other skater's bodily movements as an extension of her own. Here the argument turns on an analogy with experiences of tool use in which, on some accounts, agents experience tools as extensions of their own bodies (Maravita and Iriki 2004; Spence 2011). If a tool can be experienced as an extension of one's own body, perhaps the same is true of another's body. This makes possible what Blomberg calls socially extended intentions in action: intentions which involve another agent's bodily movements but whose contents do not involve other agent's actions. If each skater experiences the other's body as an extension of her own, she can attempt to perform a manoeuvre which involves the other's bodily movements without thereby attempting to perform an action which (from her point of view) is not her own. This explains how an agent can attempt an action which is not entirely her own: by experiencing it as it if were. Whereas many accounts of joint action emphasise the need for knowledge of other agents and their actions, Blomberg's proposal is consistent with (but does not entail) that two agents acting together might each experience themselves as acting alone. 
So far we have focused on intentions in joint action. Woodard's primary concern is with reasons for action and, in particular, with the unit of action - the unit whose qualities provide reasons for or against performing a particular action. It is quite widely assumed that the unit of action extends only to those things which an agent can control. This also appears plausible. For instance, suppose that it would be good if Ayesha and Beatrice were to lift the picnic basket together, but also that it would be disastrous if either were to lift it alone. The fact that it would be good if Ayesha and Beatrice were to lift the picnic basket, all by itself, does not seem to be a reason for Ayesha to lift it. For unless she also knows or can predict that Beatrice will lift with her, it would seem reckless of Ayesha to lift the basket. This example appears to suggest that reasons for Ayesha to act are qualities of those actions she can control, as is commonly assumed. However, as Woodard notes, proponents of team reasoning claim that humans, in deciding how to act, sometimes consider not what it would be best for them to do but what it would be best for several agents of which they are one to do (Bacharach 2006; Sugden 2000). For instance, suppose that Ayesha and Beatrice each individually have to decide at what time to picnic on a particular day, and that they can only picnic together (which they would prefer) if they decide on the same time. It could happen that each selects a time which suits her best, not considering the other's preferences except in attempting to predict when the other will picnic. But, equally, it seems easy to imagine that each individually selects a time which they take to be best for them both, all things considered. Woodard notes that, in this case, Ayesha's reasons for deciding to picnic at noon (say) are qualities of an event which involves the actions of another agent. What makes noon the time for Ayesha to picnic is that this would be an optimal time for Ayesha and Beatrice to picnic together. This illustrates how the unit of action can extend beyond the agent's own options. Woodard shows that there may be other cases not involving team reasoning in which the unit of action extends beyond an agent's own options. He also proposes that this notion of an extended unit of action serves to pick out an interesting notion of joint action on which a joint action is an "action composed of parts such that the reasons to perform each part depend on the qualities of the whole" (this issue).

Woodard's proposal is related to Pacherie's account of shared intention. Where agents act on a shared intention in Pacherie's sense, their action is joint in Woodard's sense. The converse may not hold, because, as Woodard explains, there may be extended units of action in cases which do not involve team reasoning.

Elliot presents a new problem for empirical research on joint action, one which also reveals a gap in philosophical accounts of joint action. Most research in both philosophy and psychology focuses exclusively on cases where, as when Ollie and Stan carry a piano home together, each agent's participation is necessary for an outcome to occur. That is, researchers tend to assume what Elliot refers to as the 'mutualistic paradigm'. However, as Elliot observes, humans freely play their parts in activities where no individual agent's contribution is necessary for success. For instance, committee work routinely goes on without all those involved participating, and in many cases would not lead to greatly different outcomes if one person more or less were to cooperate. Where agents know this they know that their actions are, in one sense, unnecessary. If they nevertheless cooperate, what enables them to make sense of their actions? Elliot proposes that it is not altruism but an ability to adopt 
the point of view of a participant in a practice: "a participant makes sense of his action in virtue of its being one among many others, each of which flows from the shared action or practice" (this issue). This is referred to as participant rationality. The problem, then, is to understand the evolution and development of participant rationality: how does it come about that humans are able to cooperate not only when their contribution to an activity is necessary to secure an outcome but also when their contribution is not?

Elliot's discussion of participant rationality is related to Pacherie's contribution. Both philosophers are concerned with identifying a sense in which an agent's practical reasoning can concern what is best for several agents of which she is one without necessarily thinking altruistically, and both of their proposals require the agent to identify herself as one among several (see also Gold and Sugden 2007). But Elliot offers a challenge which applies inter alia to accounts of team reasoning. For it is plausible that, in the sorts of case he considers, such as committee work, team reasoning (at least as standardly characterised; see Sugden 2000) may not lead any committee member to conclude that she herself should contribute. For those who appeal to team reasoning in explicating shared intention, Elliot's challenge is to explain how it comes about that committee members intentionally participate when it is clear that no single individual's contribution is required for success.

So far we have been concerned with questions about intention, motivation and reason in analyses of joint action. These questions are inextricably bound up with questions about psychological mechanisms for joint action. This is most evident in the case of developmental research, which has investigated the cognitive and conceptual abilities underlying joint action.

Infants engage in social interaction with adults from very early on in life but it is not until the end of their second year that children start to be able to intentionally coordinate their actions with peers independently of adult guidance. How does the ability to intentionally coordinate actions with others develop and what kinds of representations sustain joint action in young children? Brownell proposes that joint action abilities emerge as the result of a long learning process in joint engagement with adults, where adults actively structure joint activities by, for example, imposing turn-taking. Thanks to this structuring, infants gradually come to have a command of the structures, timings and communicative practices involved in joint action. The development of abilities to engage in joint action consists, at least in part, in the development of abilities to relate self and other. In accounting for early joint action abilities, Brownell argues, it may be sufficient to assume that two-year olds understand how others' actions pertain to their own goals. Such a "me with you" representation allows for coordination without requiring that children represent a goal other than their own. It may be that children only later come to represent other's goals in relation to their own goals. The notion of a "me with you" representation may help to specify minimal requirements for joint action (Vesper et al. 2010). There is also an interesting connection to Blomberg's proposal that co-actors' may experience each other's actions as extensions of their own. In Blomberg's view, others' actions are experienced as an extension of one's own, in a way similar to that in which, according to some researchers, tools are sometimes experienced as bodily extensions. Relatedly, in Brownell's account a child may treat another's actions as a "tool" extending her own action possibilities. Whereas many accounts 
of joint action stress abilities to adopt others' perspectives, Blomberg and Brownell propose that, in some cases, there need be no awareness of another's agency or goals.

As Brownell explains, early in the development of joint action there are behaviourally contingent social interactions which do not require representing others' intentions or any other mental states; these are commonly referred to as joint engagements. Seemann's contribution reveals a continued role for joint engagement in forms of joint action characteristic of adults. What is shared when two people kick along a football while going for a walk? Seemann argues that joint actions such as this one, where there is precise temporal and spatial coordination and the agents are in view of each other, involve sharing particular kinds of feelings. He argues that perceptual experience and motor engagement are "inextricably intertwined". In line with the ecological approach to perception (Gibson 1977; Marsh et al. 2009), Seemann stresses that perception is an active process that relies on the relation between individuals and the world. In joint actions such as passing a football back and forth, a person's perceptual experience is shaped by their partner's actions and attention, which are in turn related to their own. This constitutes a sharing of simple feelings, which is given when two or more individuals have perceptual experiences that are "constitutively tied not only to their own body state but also to that of the other person". Rather than two individuals having the same experiences, each person has a role in the individuation of the other's perceptual experience. According to Seemann, this sharing of simple feelings enables joint engagement. It follows that the basic unit of analysis for joint action is not the individual, but the system of interacting individuals (Marsh et al. 2009).

Like Brownell and Seemann, Michael focuses on mechanisms involved in basic cases of joint action. Michael notes that the potential role of emotions in joint action has been widely ignored, both by philosophers and by scientists. His starting point is a conceptually simple notion of shared emotion: for an emotion to be shared by two or more agents it is sufficient that one agent expresses it and the other agent or agents perceive this expression. Michael argues that the perception of expressions of emotion may serve to facilitate coordination in a variety of ways. For instance, in some cases coordination requires each agent involved in a joint action to monitor another agent's progress towards a common goal. Michael proposes that expressions of emotion, which can plausibly carry information about an agent's progress towards a goal, may be a means by which such monitoring is achieved. A further strand of Michael's paper concerns attempts to characterise forms of joint action which do not presuppose abilities to understand notions such as commitment, knowledge and intention. Here Michael argues that shared emotion may serve at least some of the functions that commitment is thought to serve in joint action. In short, emotion matters for understanding both how joint action is possible and what it is.

So far we have been concerned with mechanisms for joint action that are closely related to commonsense notions of intention, perception and emotion. Such notions are indispensable for understanding joint action but they cannot fully explain the possibility of precise coordination in space and time which is a key ingredient in many central cases of joint action from cooking together (you stir while I pour) to piano duets. This calls for understanding links between agents that arise on the basis of shared task representations, internal models, and shared motor representations. 
Imagine that Nadia and Sam have agreed to take the highway to drive to the countryside for a picnic. At the first crossing, Nadia, who is driving, needs to turn left, and at the second crossing she needs to take a right turn. As the co-driver in charge of the music, Sam may also be thinking about the turns to be made, making sure that they are on the right route. In what way, if any, is Sam's thinking about an upcoming turn similar or equivalent to the way in which Nadia is planning her actions? Is Sam's co-driving so pronounced that when the gear needs to be shifted or when Nadia needs to signal he will generate corresponding motor commands as if he were about to perform these actions himself? Psychological experiments on "task sharing" or "task co-representation" suggest that people acting next to each other form representations of each other's tasks, as indexed for instance by the increased need to inhibit an action tendency when it is the other's turn to act, compared to when it is no-one's turn to act (see Knoblich et al. 2011 for an overview). Shared action representations, in this context, are functionally equivalent representations that are active in the person who is about to act and in the co-actor who does not need to do anything. Reporting novel results and reconsidering prior findings, Wenke, Atmaca, Holländer, Liepelt, Baess and Prinz ask what exactly corepresentation entails. Their proposal is simple yet impressive in its explanatory power: When performing independent tasks as part of a joint activity, people represent that another agent is responsible for a particular task, and when it is her turn to act. They do not, however, generate specific motor representations of the particular actions to be performed by the other.

Joint actions involving precise temporal and spatial coordination between people, such as building a tower of bricks together, require additional mechanisms that allow for the prediction of others' actions. Pezzulo analyses the content of shared representations in such coordination tasks. He asks how representations become aligned during joint action and in what ways shared representations facilitate coordination. The answers to these questions inform a computational model, where representations at different levels in the action planning hierarchy become aligned across agents through internal models in the motor system. These models are used not only to generate predictions about the course and outcome of actions during performance but also during action observation. In Pezzulo's terms, a shared representation is a representation of a particular action that is activated not only in the person performing it, but also in the interaction partner. This alignment at the motor level, so Pezzulo argues, may generate alignment of higher-level cognitive representations as a by-product. A novel aspect of the model is that in addition to relying on automatic alignment processes, agents can also strategically make their actions more informative to each other to increase predictability.

\section{Outlook}

A dominant way of thinking about joint action has been to begin with notions of shared intention or collective intentionality which, as several researchers have argued (Pacherie, Michael and Blomberg in this volume; see also Knoblich and Sebanz 2008; Tollefsen, 2005; Butterfill 2011), presuppose cognitively and conceptually demanding theory of mind skills. By contrast, empirical research has focused on the 
contribution of lower-level mechanisms of coordination in explaining joint action, and on cases of joint action where full blown theory of mind skills may be absent (see contributions by Brownell, Pezzulo and Wenke et al.). Thus there is a gap between the dominant philosophical approach and the experimental investigation of joint action phenomena. Many of the contributions in this special issue can be seen as breaking away from the dominant way of thinking in ways that are motivated by recent developments in developmental and cognitive psychology. We discern two broad strategies for breaking away. One is to retain the centrality of shared intention while offering a new, potentially less demanding account of what counts as shared intention (Pacherie, Blomberg). As several of the contributions show, whether or not one accepts these less demanding accounts of shared intention there are still substantial philosophical and empirical puzzles about joint action (Smith, Elliot). A second strategy is to provide conceptual tools for investigating forms of joint action which do not involve shared intention at all (Seemann, Michael, Woodard). The two strategies are not exclusive; indeed, they are naturally seen as complementary to each other. Nor is the objective of the second strategy to eliminate appeal to sophisticated notions of shared intention altogether. The aim is rather to explore whether the most sophisticated cases could emerge from more basic forms of joint action, and, if so, how they might emerge. Addressing the full tangle of philosophical and scientific questions about joint action requires understanding not only shared intention but also the other ingredients which make joint action possible.

\section{References}

Bacharach, Michael. 2006. Beyond individual choice. Princeton: Princeton University Press.

Bratman, Michael. 1992. Shared cooperative activity. The Philosophical Review 101(2): 327-341.

Bratman, Michael. 2009. Modest sociality and the distinctiveness of intention. Philosophical Studies 144(1): 149-165.

Butterfill, Stephen 2011. Joint action and development. Philosophical Quarterly. (forthcoming).

Davidson, Donald. 1971 [1980]. Agency. In Essays on actions and events. Oxford: Oxford University Press.

Gibson, J.J. 1977. The theory of affordances. In Perceiving, acting, and knowing: toward an ecological psychology, ed. R. Shaw and J. Bransford, 67-82. Hillsdale: Erlbaum.

Gilbert, Margaret. 1992. On social facts. Princeton: Princeton University Press.

Gold, Natalie, and Robert Sugden. 2007. Collective intentions and team agency. Journal of Philosophy 104(3): 109-137.

Hamilton, A. F. d. C., and Grafton, S. T. 2007. The motor hierarchy: from kinematics to goals and intentions. In Sensorimotor Foundations of Higher Cognition, eds. Haggard P, Rossetti Y, and Kawato M. Oxford University Press.

Helm, Bennett W. 2008. Plural agents. Nous 42(1): 17-49.

Kutz, Christopher. 2000. Acting together. Philosophy and Phenomenological Research 61(1): 1-31.

Maravita, Angelo, and Atsushi Iriki. 2004. Tools for the body (schema). Trends in Cognitive Sciences 8(2): 79-86.

Knoblich, G., S. Butterfill, and N. Sebanz. 2011. Psychological research on joint action: theory and data. In The psychology of learning and motivation, vol. 54, ed. B. Ross, 59-101. Burlington: Academic.

Knoblich, Guenther, and Natalie Sebanz. 2008. Evolving intentions for social interaction: from entrainment to joint action. Philosophical Transactions of the Royal Society B 363: 2021-2031.

Marsh, K.L., M.J. Richardson, and R.C. Schmidt. 2009. Social connection through joint action and interpersonal coordination. Topics in Cognitive Science 1(2): 320-339. 
Roth, Abraham Sesshu. 2004. Shared agency and contralateral commitments. The Philosophical Review 113(3): 359-410.

Searle, John R. 1990 [2002]. Collective Intentions and Actions. In Consciousness and Language. Cambridge: Cambridge University Press.

Spence, Charles. 2011. Tool use and the representation of peripersonal space in humans. In Tool Use and Causal Cognition, eds. McCormack T., Hoerl C. and Butterfill S. Oxford University Press.

Sugden, Robert. 2000. Team preferences. Economics and Philosophy 16: 175-204.

Tollefsen, Deborah (2005). Let's pretend: Children and joint action. Philosophy of the Social Sciences, 35(75): 74-97.

Tomasello, Michael, and Hannes Rakoczy. 2003. What makes human cognition unique? From individual to shared to collective intentionality. Mind and Language 18(2): 121-147.

Vesper, C., S. Butterfill, G. Knoblich, and N. Sebanz. 2010. A minimal architecture for joint action. Neural Networks 23: 998-1003.

Wolpert, D.M., K. Doya, and M. Kawato. 2003. A unifying computational framework for motor control and social interaction. Philosopical Transactions of the Royal Society London B Biological Sciences 358(1431): 593-602. 